\title{
Synthesis of site-heterologous haptens for high-affinity anti- pyraclostrobin antibody generation
}

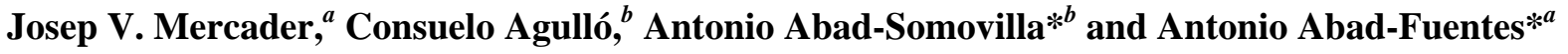 \\ Received (in $X X X, X X X) X$ th $X X X X X X X X X 200 X$, Accepted $X$ th $X X X X X X X X X 200 X$ \\ ${ }_{5}$ First published on the web Xth $X X X X X X X X X 200 X$ \\ DOI: 10.1039/b000000x
}

The design and synthesis of functional chemical derivatives of small organic molecules is usually a key step for the intricate production of a variety of bioconjugates. In this respect, the derivatization site at which the spacer arm is introduced in immunizing conjugates constitutes a highly critical parameter for the generation of high-affinity and selective antibodies.

${ }_{10}$ However, due to the usual complexity of the required synthetic procedures, the appropriate comparison of alternative tethering positions has often been neglected. In the present study, meticulous strategies were followed to prepare synthetic derivatives of pyraclostrobin with the same linkers located at diverse rationally-chosen sites. Activity appraisal of antibodies and bioconjugates was carried out by bidimensional competitive direct and indirect immunoassays, and a superior performance of two of the three synthesized haptens was found. Finally, a detailed analysis of the conformations of the target molecule and the 15 synthesized haptens in aqueous solution was done using computer assisted molecular modeling techniques. This study suggested that the lower titers and affinities of one set of antibodies are most probably due to conformational effects of the spacer arm in the immunizing bioconjugate.

\section{Introduction}

20 The production of high-affinity and selective binders to small organic molecules is a biotechnological research field of huge importance for such diverse disciplines as drug discovery, clinical diagnostics, food safety, and environmental monitoring. Antibodies are the paradigm of binding proteins ${ }_{25}$ due to their exquisite molecular recognition ability. Long ago, Nobel-prize winner Karl Landsteiner was the first to discover that low molecular weight compounds become immunogenic only after association with a carrier protein, coining the term hapten for these substances. ${ }^{1}$ Because small organic molecules 30 usually lack ready-to-activate chemical groups for protein conjugation, the generation of high-quality antibodies exhibiting the desired ligand-binding features strongly relies on the synthesis of suitable functional derivatives of the target analyte. Such synthetic derivatives should closely mimic the 35 target ligand, maximizing the steric, hydrophobic, and electronic similarity to the parent molecule. Most commonly, synthetic haptens incorporate a spacer arm to better display the molecule, thus facilitating its recognition by the receptor, despite the fact that direct coupling of the analyte to the 40 carrier protein, when possible, has occasionally been employed. ${ }^{2}$ Although the physico-chemical characteristics of the analyte determine the optimum properties of the spacer arm for hapten conjugation, linear aliphatic bridges are known to cause negligible interferences over the production of 45 antibodies if an optimum length of two to six carbon atoms is maintained. ${ }^{3}$ Nevertheless, a critical parameter for the production of antibodies is, most noteworthy, the derivatization site; that is, the position at which the spacer arm is attached to the molecule. The linker position will mold 50 the final conformation of the conjugate and therefore, it will settle the specific moieties that will be accessible for binding. Even if these general considerations are simple and qualitative, they have generally been extremely useful - in combination with rational and judicious chemical examination 55 of the target molecule by qualified chemists - for the synthesis of appropriate haptens and bioconjugates applied to the production of antibodies with the desired binding properties. Lately, molecular modeling techniques are being
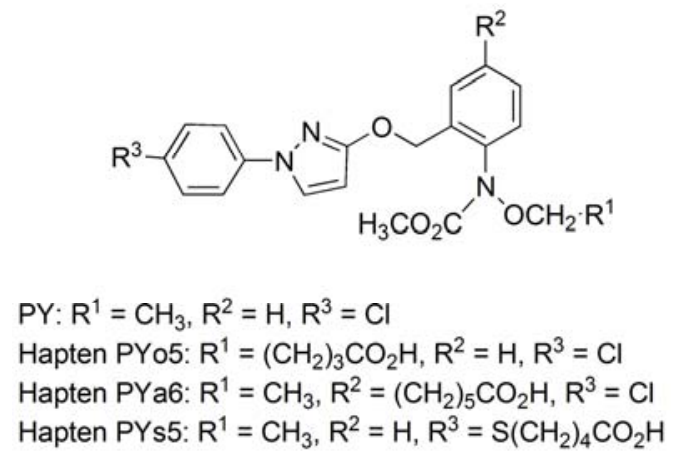

$60 \quad$ Figure 1 Structure of PY and the three synthetic haptens.

increasingly used as complementary tools to assist researchers in, for instance, the prediction of the best hapten structures for immunoconjugate preparation or the interpretation of experimental results regarding affinity or selectivity of 65 receptors. ${ }^{4}$

Strobilurins are a new class of synthetic biocides displaying outstanding properties and a new mode of action, so the introduction of the first strobilurin fungicides in 1996 meant a significant contribution to the fight against fungal diseases. ${ }^{5}$ 70 As part of an ongoing project aimed at obtaining high-affinity antibodies and developing immunochemical methods to selectively detect the most relevant chemicals of the strobilurin family of pesticides, we chose pyraclostrobin (PY) as a model analyte to ascertain the influence of the spacer arm 75 attachment site on the affinity of the derived antibodies. PY is considered as a second generation strobilurin fungicide, and it is composed of a methoxycarbamate toxophore moiety, an aryl bridge, and a characteristic two-ring system (Figure 1). In this article, we describe the synthesis of PY derivatives with 80 the spacer arm located at different sites of the molecule. To rigorously compare the suitability of these synthetic haptens for inducing the formation of high-affinity antibodies, a homogenous linker of comparable length and composition was used for coupling to the same carrier protein. Very few ${ }_{85}$ examples have been found in the literature in which the same spacer arm was used to prepare several functionalized haptens 


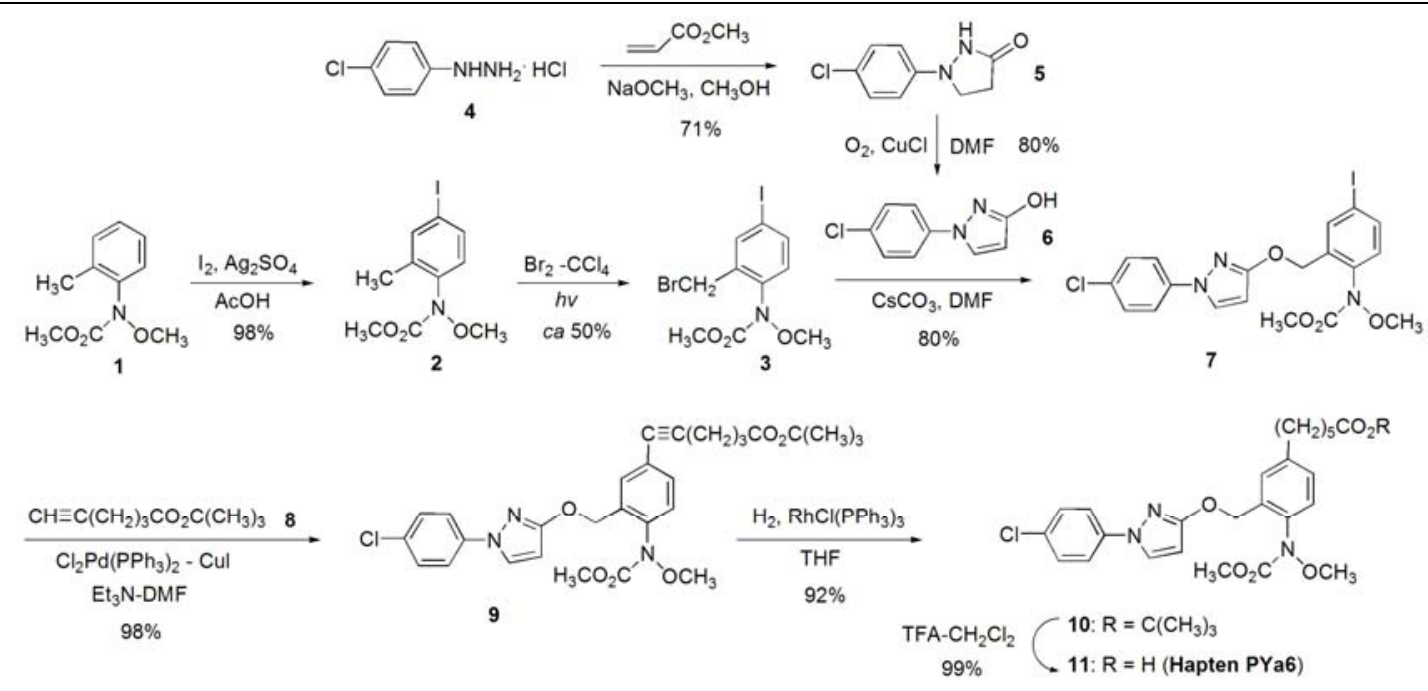

Scheme 1 Synthesis of hapten PYa6.

through different derivatization sites in order to find the 5 optimum orientation of the molecule. ${ }^{6}$ Antisera, representing the unbiased whole-response of the animal immune system, were chosen as the source of antibodies. The affinity and selectivity of the generated reagents were evaluated by competitive enzyme-linked immunosorbent assay (cELISA) 10 using the conjugate-coated indirect and the antibody-coated direct formats. Finally, our results were assessed with computer-generated molecular models of the target molecule and the synthesized haptens.

\section{${ }_{15}$ Results and discussion}

\section{Chemistry}

After a rational examination of the planar structure of PY (Figure 1), three key positions for the introduction of the spacer arm and analyte functionalization became readily 20 apparent: the methoxycarbamate toxophore moiety, the arylic bridge, and the chlorophenyl moiety. Accordingly, three PY analogues, namely, PYo5, PYa6, and PYs5 (Figure 1), were proposed as haptens for the production of high-affinity antibodies. All three structures maintained the complete

25 hydrocarbon skeleton and the most characteristic functional groups of the analyte, incorporating the hydrocarbon spacer arm at positions where minimum modifications of steric and electronic properties of the molecule were expected. Moreover, the length and composition of the spacer arms were 30 nearly identical in all three haptens. The synthesis of haptens PYa6 and PYs5 is herein reported for the first time, whereas the preparation of hapten PYo5 was previously described by our group in a study dealing with the influence of the spacer arm length on antibody production. ${ }^{7}$ In hapten PYa6, the

35 spacer arm is directly attached to the aryl ring that contains the methoxycarbamate group through a single carbon-carbon bond, while in hapten PYs5 the hydrocarbon spacer chain is bonded to the other (opposite) aryl group through a sulphur bridge that replaced the chlorine atom of PY. A preliminary 40 examination of the synthetic routes required for the preparation of haptens PYa6 and PYs5 evidenced that rather laborious and multi-step schemes would be required to prepare these analogues. Initial attempts to introduce the spacer arm at the required positions directly on PY failed, so 45 haptens had to be finally prepared by total synthesis starting from ready available materials. We used an adaptation of the strategy previously reported for the preparation of $\mathrm{PY}^{8}$ and related compounds, ${ }^{9}$ which involved, for such cases, the alkylation of a 1-aryl-1H-pyrazol-3-ol with a methyl so 2-(bromomethyl)-phenyl(methoxy)carbamate as the key synthetic step for the elaboration of the characteristic PY framework.

The synthesis of hapten PYa6 (11) began with the iodination reaction of methyl methoxy(o-tolyl)carbamate (1) using iodine 55 and silver sulphate in $\mathrm{AcOH}$ (Scheme 1). This reaction is highly efficient and regioselective, affording exclusively the 4-iodo compound 2. Radical benzylic bromination of $\mathbf{2}$ with $\mathrm{N}$-bromosuccinimide and azobisisobutyronitrile as the initiator under standard thermal conditions afforded a very low yield of 60 the desired benzylic bromide, a result that contrasted with that obtained in the bromination reaction of the non iodinated analogue (see below). However, an acceptable yield of benzyl bromide 3 was obtained when the free radical bromination of iodide 2 was undertaken with bromine under radiation65 induced conditions at room temperature. Under these conditions, the reaction afforded a mixture of bromide $\mathbf{3}$ and unreacted starting material, together with minor amounts of the corresponding benzylic dibrominated derivative, which could not be separated by conventional chromatographic 70 methods, so it was used as such in the following step. Thus, the expected benzyl ether 7 was obtained in excellent yield from the reaction of this mixture with 1-(4-chlorophenyl)-1H-pyrazol-3-ol (6), readily prepared according to a literature procedure ${ }^{10}$ by reaction of 75 (4-chlorophenyl)hydrazine hydrochloride (4) with methyl acrylate and oxidation of the resulting pyrazolidinone $\mathbf{5}$ with oxygen and catalytic $\mathrm{CuCl}$ in about $57 \%$ overall yield. Once the tricyclic ring system present in PY had been prepared, the synthesis of hapten PYa6 was completed via substitution of so the iodine atom in 7 by the $\mathrm{C} 6$ hydrocarbon chain using palladium catalyzed coupling methodology. Thus, Sonogashira cross-coupling of iodide 7 with alkyne tert-butyl ester 8 under standard conditions afforded the acetylenic compound 9, which was hydrogenated using Wilkinson's 85 catalyst to give compound $\mathbf{1 0}$ in $90 \%$ overall yield for the two steps. The synthesis of hapten PY6a was completed by hydrolysis of the tert-butyl ester group of 10, which took place in nearly quantitative yield by treatment with trifluoroacetic acid at $0{ }^{\circ} \mathrm{C}$. 


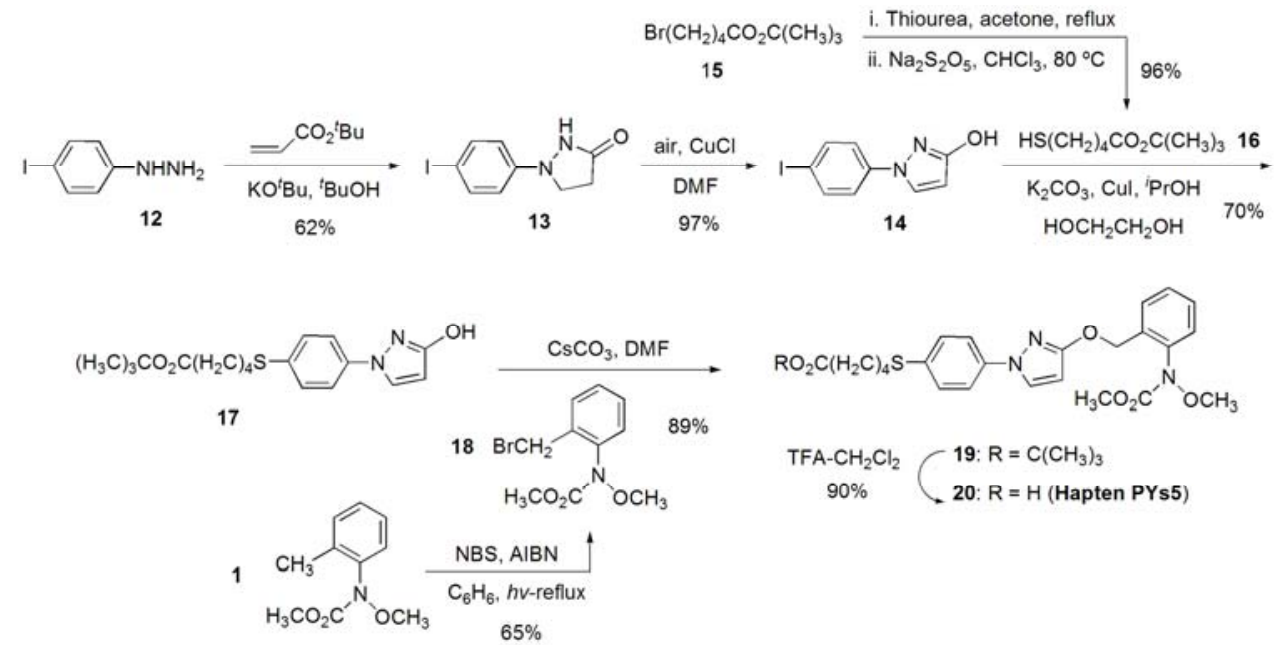

Scheme 2 Synthesis of hapten PYs5.

carrier proteins by standard procedures (see experimental part). The hapten-to-protein molar ratios (MR) of the three 35 bioconjugates to bovine serum albumin (BSA) were determined by differential absorbance measurements and MALDI-TOF-MS. Similar values were retrieved by both analytical methods (Table 1) as also observed by other authors, ${ }^{12}$ except for the MR of BSA-PYa6 when calculated

The synthesis of hapten PYs5 (20) began with the 5 preparation of 1-(4-iodophenyl)-1H-pyrazol-3-ol (14) (Scheme 2), which was obtained from (4-iodophenyl)hydrazine (12) via a two step process involving condensation with tert-butyl acrylate catalyzed by potassium tert-butoxide and subsequent oxidation of the obtained 10 dihydropyrazolone $\mathbf{1 3}$ with air catalyzed by $\mathrm{CuCl}$. The pyrazolol 14 was obtained with an overall yield of about $60 \%$. Replacement of the iodine atom in $\mathbf{1 4}$ by the alkyl sulfide chain was efficiently carried out by $\mathrm{Cu}$-catalyzed cross-coupling reaction of the aryl iodide with the thiol 16, 15 which was in turn prepared from tert-butyl 5-bromopentanoate (15) and thiourea in very high yield via formation of the thiouronium salt followed by cleavage with sodium pyrosulfite. ${ }^{11}$ The synthesis of the whole framework of hapten PYs5 was completed by alkylation of the pyrazolol 20 moiety of $\mathbf{1 4}$ with the known methyl 2-(bromomethyl)phenyl(methoxy)carbamate (18) in a similar way to that described above for the other hapten. Under these conditions, the alkylation reaction afforded the tert-butyl ester 19 in an excellent $89 \%$ yield. Finally, acid hydrolysis of the 25 tert-butyl ester group of $\mathbf{1 9}$ by trifluoroacetic acid treatment gave the desired hapten PYs5 (20) with also an excellent yield.

\section{Bioconjugates and antibodies}

The hapten density of the immunogenic conjugates is a 30 fundamental parameter that determines the titer and the affinity of the generated antibodies. Hapten's carboxyl groups were activated for coupling to the $\varepsilon$-amine residues of the
40 by differential absorption, which seemed to be overestimated. Anyhow, equivalent MRs for the three immunogens were found as required for a proper comparison of the immune response. The observed MRs of our BSA conjugates were in the same range as the optimum MRs for immunogenic ${ }_{45}$ conjugates determined by Boro et al. ${ }^{13}$ using the same carrier protein. For assay conjugates, carrier proteins different to the immunogen are demanded, so ovalbumin (OVA) and horseradish peroxidase (HRP) were employed. Considering the calculated MRs of these conjugates, it could also be seen ${ }_{50}$ that both of the PYa6 assay conjugates were slightly higher than those of the other haptens, as it happened with the BSA-PYa6 conjugate. Unfortunately, the MRs of OVA conjugates could not be determined by MALDI-TOF-MS, and the same mass spectra were obtained for the unconjugated and 55 the conjugated HRP samples, probably due to the low density of hapten molecules in the conjugates. In any case, all assay (HRP and OVA) conjugates behaved correctly in the cELISA at usual concentrations, demonstrating that they carried sufficient hapten molecules for adequate assay performance.

\begin{tabular}{|c|c|c|c|c|}
\hline \multirow[b]{2}{*}{ Hapten } & \multicolumn{2}{|c|}{ BSA } & \multirow{2}{*}{$\frac{\text { OVA }}{\text { Abs. }}$} & \multirow{2}{*}{$\begin{array}{l}\text { HRP } \\
\text { Abs. }\end{array}$} \\
\hline & Abs. $^{b}$ & MALDI $^{\mathrm{c}}$ & & \\
\hline PYo5 & 19 & 12 & 5 & 4 \\
\hline PYa6 & 25 & 15 & 8 & 6 \\
\hline PYs5 & 17 & 17 & 6 & 3 \\
\hline
\end{tabular}

${ }^{a}$ Hapten densities were calculated as moles of hapten per mole of protein. ${ }^{\mathrm{b}}$ Hapten densities retrieved by differential absorbance measurements. ${ }^{\mathrm{c}}$ Hapten densities calculated by MALDI-TOF-MS

Table 2 Assay parameters achieved with homologous conjugates in the two cELISA formats

\begin{tabular}{|c|c|c|c|c|c|c|}
\hline \multirow[b]{2}{*}{ Antiserum } & \multicolumn{3}{|c|}{ Indirect cELISA $^{\mathrm{a}}$} & \multicolumn{3}{|c|}{ Direct cELISA $^{b}$} \\
\hline & $\begin{array}{c}\text { Antiserum } \\
\text { dilution }\left(\times 10^{3}\right) \\
\end{array}$ & $A_{\max }$ & $\mathrm{IC}_{50}$ & $\begin{array}{l}\text { TTracer }] \\
(\mathrm{ng} / \mathrm{mL}) \\
\end{array}$ & $A_{\max }$ & $\mathrm{IC}_{50}$ \\
\hline rPYo5\#1 & 30 & $1.40 \pm 0.29$ & $4.9 \pm 2.0$ & 300 & $0.94 \pm 0.09$ & $10.2 \pm 0.9$ \\
\hline rPYo5\#2 & 30 & $1.24 \pm 0.14$ & $6.8 \pm 1.8$ & 100 & $0.93 \pm 0.26$ & $8.4 \pm 2.6$ \\
\hline rPYa6\#1 & 3 & $0.90 \pm 0.25$ & $14.4 \pm 4.5$ & 300 & $0.87 \pm 0.01$ & $>100$ \\
\hline rPYa6\#2 & $10^{\mathrm{c}}$ & $1.19 \pm 0.01$ & $43.0 \pm 5.9$ & 300 & $0.46 \pm 0.07^{\mathrm{d}}$ & $>100$ \\
\hline rPYs5\#1 & 10 & $0.92 \pm 0.33$ & $5.0 \pm 1.0$ & 30 & $1.38 \pm 0.18$ & $6.9 \pm 1.1$ \\
\hline rPYs5\#2 & 10 & $0.85 \pm 0.09$ & $1.7 \pm 0.8$ & 10 & $0.86 \pm 0.12$ & $1.5 \pm 0.3$ \\
\hline
\end{tabular}

${ }^{\mathrm{d}} \mathrm{A}_{\max }$ above 0.5 could not be reached. 


\begin{tabular}{|c|c|c|c|c|c|c|c|c|}
\hline \multirow[b]{2}{*}{ Antiserum } & \multicolumn{4}{|c|}{ Indirect cELISA $^{\mathrm{b}}$} & \multicolumn{4}{|c|}{ Direct cELISA $^{c}$} \\
\hline & $\begin{array}{c}\text { OVA } \\
\text { conjugate }\end{array}$ & $\begin{array}{c}\text { Antiserum } \\
\text { dilution }\left(\times 10^{3}\right) \\
\end{array}$ & $A_{\max }$ & $\mathrm{IC}_{50}(\mathrm{nM})$ & $\begin{array}{c}\text { HRP } \\
\text { conjugate }\end{array}$ & $\begin{array}{l}{[\text { Tracer] }} \\
(\mathrm{ng} / \mathrm{mL})\end{array}$ & $A_{\max }$ & $\mathrm{IC}_{50}(\mathrm{nM})$ \\
\hline rPYo5\#1 & PYa6 & 30 & $1.23 \pm 0.22$ & $2.4 \pm 0.3$ & PYa6 & 300 & $1.01 \pm 0.10$ & $6.3 \pm 0.5$ \\
\hline rPYo5\#2 & PYa6 & 10 & $1.57 \pm 0.14$ & $6.2 \pm 1.4$ & PYa6 & 300 & $0.91 \pm 0.22$ & $22.2 \pm 6.1$ \\
\hline rPYa6\#1 & PYo5 ${ }^{\mathrm{d}}$ & 3 & $1.01 \pm 0.32$ & $7.5 \pm 4.0$ & & & & \\
\hline rPYa6\#2 & PYo5 & 30 & $0.95 \pm 0.09$ & $15.4 \pm 1.9$ & & & & \\
\hline rPYs5\#1 & РYa6 & 3 & $1.28 \pm 0.32$ & $4.2 \pm 0.9$ & & & & \\
\hline
\end{tabular}

rPYs5\#2

${ }^{a}$ Only results of those immunoreagent combinations that afforded $\mathrm{A}_{\max }$ values over 0.5 are given. ${ }^{\mathrm{b}}$ Coating conjugate was at $1.0 \mu \mathrm{g} / \mathrm{mL} .{ }^{\mathrm{c}}$ Antibody dilution was $1 / 3000 .{ }^{\mathrm{d}}$ Coating conjugate concentration was $0.1 \mu \mathrm{g} / \mathrm{mL}$.

Six rabbits were immunized and blood samples were collected after the third immunization. Titers of the two BSA-PYa6 immunized animals were approximately $10^{4}$, whereas those of animals immunized with BSA-PYs5 and 5 BSA-PYo5 were around 10 and 50 times higher, respectively. The titers did not improve after the fourth immunization, and consequently the animals were exsanguinated. Finally, two antisera were generated from each immunogen: antisera rPYa6\#1 and \#2 from immunogen BSA-PYa6, antisera 10 rPYo5\#1 and \#2 from immunogen BSA-PYo5, and antisera rPYs5\#1 and \#2 from immunogen BSA-PYs5.

The influence of the derivatization site of assay conjugates was evaluated for the two most common cELISA formats. Depending on the ELISA format, OVA-hapten conjugates 15 were used as passive immobilized competitive reagent for indirect assays whereas HRP-hapten conjugates were employed as enzyme tracer conjugates in direct assays. The binding properties of the generated polyclonal antibodies were initially evaluated as the $\mathrm{IC}_{50}$ value of the inhibition curve that 20 was retrieved in homologous competitive assays with PY as free analyte (Table 2). Standard curves were run using an array of concentrations of the antibody and the assay conjugate, so that a family of inhibition curves was generated; one curve for each combination of immunoreagents. This

25 approach enabled a simultaneous, and therefore comparable, determination of the $\mathrm{IC}_{50}$ values under different experimental conditions, so information about antibody affinity was rapidly acquired without a previous titration assay. We found that, in the conjugate-coated indirect format, the antisera generally 30 performed better (lower $\mathrm{IC}_{50}$ values) when OVA-hapten conjugates were employed at $0.1 \mu \mathrm{g} / \mathrm{mL}$ (Table 2). Under optimum conditions for each combination of immunoreagents, antibodies derived from haptens PYo5 and PYs5 recognized PY with a similar affinity, with antiserum rPYs5\#2 displaying 35 the lowest $\mathrm{IC}_{50}$ value $(1.7 \mathrm{nM})$. On the contrary, antisera from hapten PYa6 showed lower affinity. These divergent results were even more evident in the antibody-coated direct format, in which antibodies from hapten PYa6 clearly did not perform as advantageously as the antibodies derived from the two 40 other haptens. Figure 2 shows the standard curve for the optimized assay in the antibody-coated direct cELISA format resulting from the combination of antiserum rPYs5\#2 with its homologous tracer HRP-PYs5. This assay afforded a theoretical limit of detection of $0.13 \mathrm{nM}(50 \mathrm{ng} / \mathrm{L})$.

45 The antibody apparent affinity that results from the calculated $\mathrm{IC}_{50}$ values may be influenced by the hapten conjugate that is used for solid phase coating in indirect assays or that is coupled to the enzyme in direct assays. Therefore, cELISAs were also undertaken with heterologous 50 conjugates for each antiserum (Table 3). Both, PYs5-type antisera and PYo5-type antisera recognized the coating OVA-PYa6 conjugate. However, very modest improvements of the $\mathrm{IC}_{50}$ values, if any, were observed with these heterologous assays as compared with the corresponding 55 homologous combinations. On the contrary, PYa6-type antisera did increase their apparent affinity to PY with heterologous OVA conjugates. As expected, the antibodycoated direct format was much more demanding about using heterologous haptens because no binding (or not enough 60 binding) to the tracer conjugate was observed in most cases. As a matter of fact, heterologous direct assays could only be developed with PYo5-derived antibodies in combination with the enzyme tracer HRP-PYa6 (Table 3). Interestingly, antiserum rPYs5\#2, displaying the highest affinity to PY in 65 the homologous assays, was the only antibody unable to recognize any heterologous haptens. Overall, the same conclusion was deduced from homologous and heterologous assays; that is, PYo5 and PYs5 haptens performed better as immunogens than hapten PYa6.

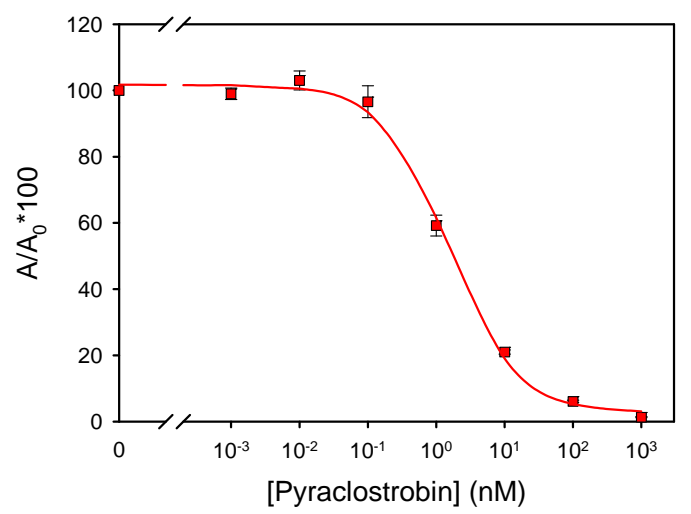

Figure 2 Standard curve for the optimized direct cELISA using antiserum rPYs5\#2 and the homologous tracer. The $\mathrm{A}_{\max }$ value was 0.84 . Values are the mean of three independent experiments.

For selectivity studies, competitive assays were run in the 75 conjugate-coated indirect format with all of the antibodies at the selected immunoreagent concentrations to give $\mathrm{A}_{\max }$ values between 1.0 and 1.5 and using PY and other analytes as competitors. Homologous conjugates were used in each case at $0.1 \mu \mathrm{g} / \mathrm{mL}$, except for antiserum $\mathrm{rPYa} \# \# 2$, for which the ${ }_{80}$ OVA-PYa6 conjugate was used at $1.0 \mu \mathrm{g} / \mathrm{mL}$. Remarkably, no member of the strobilurin family other than PY was recognized by any of the antisera, disregarding the derivatization site of the immunogen. All of the strobilurin fungicides (azoxystrobin, picoxystrobin, kresoxim-methyl, 85 trifloxystrobin, dimoxystrobin, fluoxastrobin, and orysastrobin) were assayed up to $1 \mu \mathrm{M}$. The selectivity of the six antisera towards other fungicides like boscalid, famoxadone, fenamidone, or cyazofamid, which are 
commonly formulated together with PY, was also investigated. Again, none of the antisera bound any of these compounds.

\section{Computational analysis}

${ }_{5} \mathrm{PY}$ is a medium-sized hapten with a very high degree of conformational flexibility due to the large number of bonds that display free rotation (see Table 1SI in the $\mathrm{ESI}^{\dagger}$ ). As a previous step to study the molecular properties of the functionalized haptens, the lowest-energy conformers of PY in 10 water were determined using computer assisted techniques. This molecular search resulted in a large amount of conformers (see Figure 1SI), which were processed and analyzed as described in the experimental part (see the section for determination of minimum-energy conformations). ${ }_{15}$ Figure 3 depicts the optimized geometry $\left(\mathrm{PM} 3-\mathrm{H}_{2} \mathrm{O}\right)$ of the conformer that displayed the lowest energy value (refer to Figure 2SI for the geometries of the other minimum-energy conformers, their classification and selection). Interestingly, the PY molecule, like the natural strobilurin A and several of 20 its analogues, ${ }^{14}$ does not adopt an extended geometry in solution. All minimum-energy conformations were characterized by two planar moieties - one plane was formed by the chlorophenyl and pyrazolyloxy moieties and the other plane was formed by the ortho-substituted benzene ring - with 25 an angle between them varying from 100 to 120 degrees. A more accurate representation of the true shape of PY is given by the electron density isosurface showed in the bottom of Figure 3 which also reflects the electrostatic potential at every point on the surface. Electronic distribution and geometry are 30 objective criteria to assist hapten design and interpret antibody behavior. Our experimental data clearly evidenced the advantage of haptens PYo5 and PYs5 over PYa6 with regard to the production of anti-PY antibodies (Tables 2 and $3)$. Sanvicens et al. ${ }^{15}$ found that the best antibody for
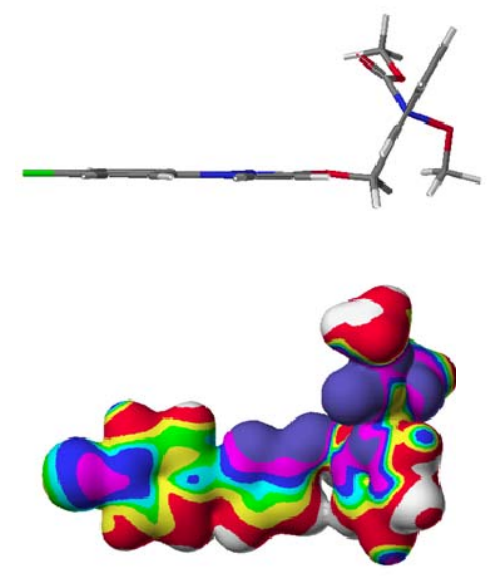

35 Figure 3 Two views of the lowest energy conformer found for PY observed from two different points of view. In the upper structure, the elements are represented in the following manner: carbon, grey; oxygen, red; nitrogen, blue; and chlorine, green. The lower structure represents the electron density surface colored by electrostatic 40 potential of a different view of the most stable conformation of PY. The energy values [in atomic units $(\mathrm{au})$ ] at each color interface are: white-red, +0.09 au; red-yellow, +0.02 au; yellow-green, +0.01 au; green-light blue, 0.00 au; light blue-dark blue, -0.01 au; dark blue-pink, $-0.03 \mathrm{au}$; pink-violet, $-0.06 \mathrm{au}$; where $1 \mathrm{au}=627.503$ $45 \mathrm{kcal} / \mathrm{mol}$. trichloroanisol was obtained with an immunizing hapten in which the spacer arm had been introduced by substitution of a $\mathrm{C}-\mathrm{Cl}$ bond by a $\mathrm{C}-\mathrm{C}$ linkage - which made the aromatic carbon atom much more positive. In contrast, the electronic so distribution played a major role in the production of antibodies against trichlorophenol. ${ }^{6 \mathrm{~b}}$ To gain some insights into the molecular reasons underlying our results, the electronic properties of the three haptens were simulated by attaching the linkers to the appropriate position of the lowest55 energy PY conformer. As depicted in Figure 4, the introduction of the spacer arm did not cause a significant alteration of the atomic charges, and very close electronic similarities between PY and the immunizing haptens were found. In hapten PYs5, the hydrocarbon spacer chain is 60 tethered to the benzene ring through a sulfur bridge that replaced the chlorine atom of PY. This substitution meant the highest observed modification of the electronic properties compared with the two other haptens (the partial charge at $\mathrm{C} 1$ in PYs5 changed by 37\%). Nevertheless, this sort of ${ }_{65}$ replacement, which has been previously used for the design of haptens for chlorine-containing analytes, ${ }^{16}$ is less drastic than if a $\mathrm{C}-\mathrm{C}$ bond had been formed. In addition, the antibody with the highest affinity to PY was derived from hapten PYs5, so electronic charges did not accounted by themselves for the 70 observed differences among immunizing haptens.

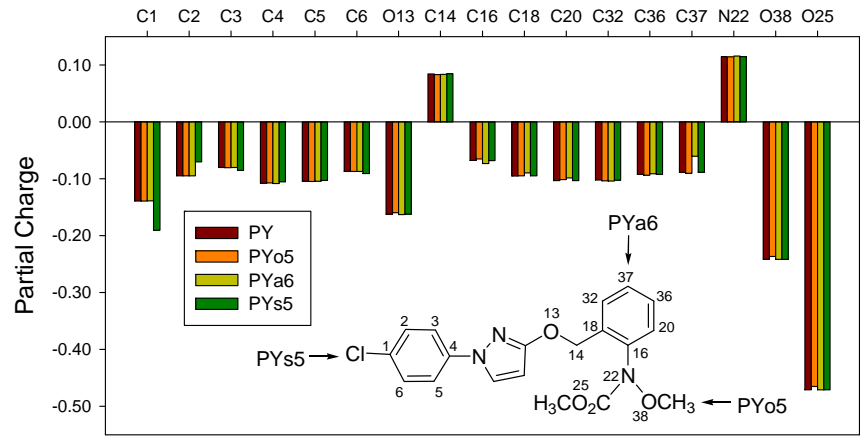

Figure 4 Computed partial atomic charges of PY and haptens PYo5, PYa6 and PYs5. Only those atoms showing a charge variation higher than $1 \%$ between PY and any of the haptens are depicted. Hydrogens 75 are not included.

As a further step to understand the reason why hapten PYa6 was a poorer mimic of the PY molecule than haptens PYo5 and PYs5, the structure of the three synthesized haptens was modeled taking into account the flexibility of the spacer $80 \mathrm{arm}$. In order to simplify this analysis, we assumed that in the synthetic haptens the common PY framework can adopt a conformational disposition similar to that of PY itself. A preliminary estimation of the preferred orientation of the spacer arm in each hapten was done by calculating the 85 conformer with the lowest energy in aqueous solution when the two first $\mathrm{C}-\mathrm{C}$ bonds of the spacer arm proximal to the backbone of the PY molecule were rotated independently $360^{\circ}$ in $15^{\circ}$ increments. From this study, we observed that the minimum energy conformers for haptens PYo5 and PYs5 90 showed a trend to display the linker away from the backbone of the molecule. On the contrary, the lowest energy conformers of PYa6 showed that the linker has a certain tendency to bend over the molecule (Figure 5), a finding that provides a feasible explanation for the inferior performance of 95 the PYa6 derivative as immunizing hapten. 

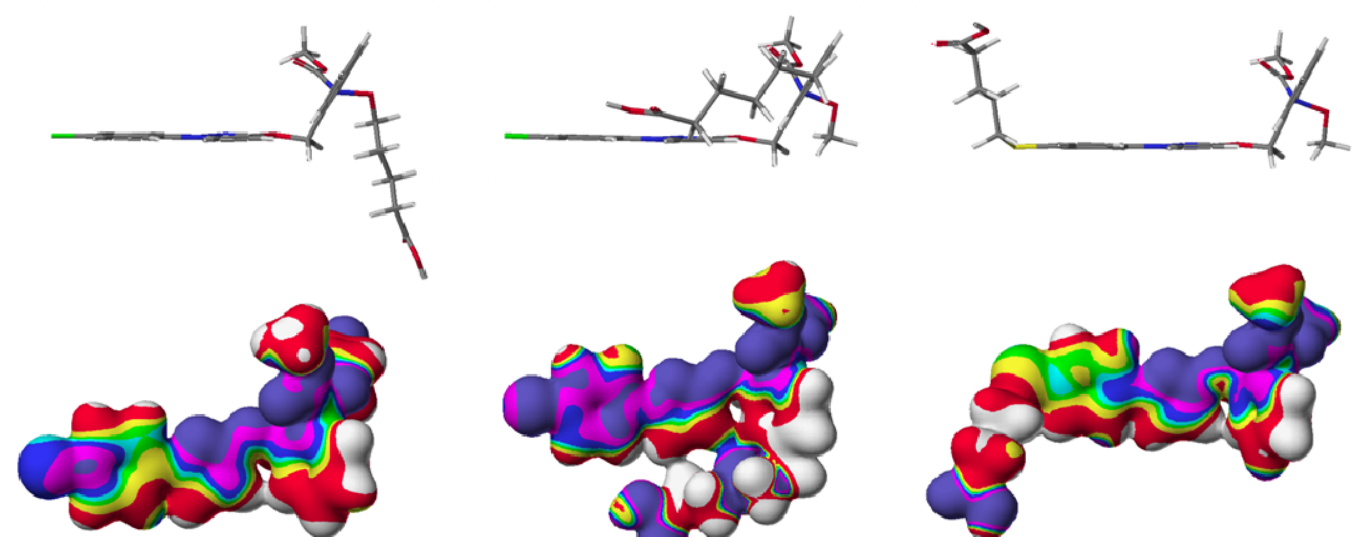

Figure 5 Most probable geometries and electron density surfaces colored by electrostatic potential from two different views of the three synthesized haptens. Color codes are the same as in Figure 3.

\section{Conclusions}

In order to obtain antibodies endowed with appropriate binding properties to small organic molecules, optimal 5 functionalized derivatives of the target analyte must be prepared. In the present study, multistep synthetic routes were carried out for a better understanding of the importance of the derivatization site. Molecular modeling studies indicated that, in the case of haptens PYo5 and PYs5, the spacer arm

10 facilitated an adequate exposure of the skeleton of PY during the immune response. On the contrary, the central position of the linker in the molecule of PYa6 could have caused steric hindrance that impaired the formation of a deep and tight binding pocket, typical of most antibody-hapten 15 interactions. ${ }^{17}$ Therefore, interactions between the linker arm and the backbone of the molecule may occur not only if too long spacers are employed, as demonstrated in our previous paper, ${ }^{5}$ but also because of an inappropriate tethering site. Acquisition of a larger body of knowledge and more profound 20 studies are required in order to better understand the factors influencing the formation and stabilization of the antibody-analyte complex. In practice, these antisera particularly those derived from haptens PYo5 and PYs5 should become very useful reagents for the preparation of 25 immunoaffinity columns intended for PY purification and concentration, as well as for the development of immunochemical methods enabling the selective and sensitive determination of PY in incurred real samples.

\section{${ }_{30}$ Experimental}

PY [methyl \{2-[1-(4-chlorophenyl)pyrazol-3-yloxymethyl]phenyl $\}$ methoxy carbamate] (CAS Registry No. 175013-18-0, MW $387.8 \mathrm{~g} / \mathrm{mol}$ ) was purchased, Pestanal grade, from Riedel-de-Haën (Seelze, Germany). The methyl 35 methoxy(o-tolyl)carbamate (1) used in this work was kindly provided by BASF AG (Limburgerhof, Germany). tert-Butyl hex-5-ynoate (8) and tert-butyl 5-bromopentanoate (15) were prepared from commercial hex-5-ynoic acid ${ }^{18}$ and 5bromopentanoic acid, respectively. ${ }^{19}$ Methyl 40 2-(bromomethyl)phenyl(methoxy) carbamate (18) was prepared from tolylcarbamate $\mathbf{1}^{20}$ All melting points were determined using a Kofler hot-stage apparatus or a Büchi melting point apparatus and are uncorrected. All NMR spectra were recorded in $\mathrm{CDCl}_{3}$ or acetone- $d_{6}$ at $\mathrm{rt}$ on a Bruker AC${ }_{45} 300$ spectrometer $\left(300.13 \mathrm{MHz}\right.$ for ${ }^{1} \mathrm{H}$ and $75.47 \mathrm{MHz}$ for $\left.{ }^{13} \mathrm{C}\right)$. The spectra were referenced to residual solvent protons in the ${ }^{1} \mathrm{H}$ NMR spectra $(7.26$ and $2.05 \mathrm{ppm})$ and to solvent carbons in the ${ }^{13} \mathrm{C}$ NMR spectra (77.0 and $\left.30.83 \mathrm{ppm}\right)$.
Infrared spectra were measured as thin films between $\mathrm{NaCl}$ ${ }_{50}$ plates for liquid compounds and as $\mathrm{KBr}$ pellets for solids using a Nicolet Avatar 320 spectrometer. Electron-impact (EI) and fast atom bombardment (FAB) mass spectra (MS and HRMS) were obtained with a Micromass VG Autospec spectrometer. ELISA absorbances were read with a ${ }_{55}$ PowerWave HT microplate reader from BioTek Instruments (Winooski, VT). A Voyager De-Pro workstation from Applied Biosystems was used for the analysis of the molecular weight of protein conjugates by matrix-assisted laser desorption ionization time-of-flight mass spectrometry (MALDI-TOF$60 \mathrm{MS})$.

\section{Determination of minimum-energy conformations}

The initial generation of low-energy conformations and geometry optimizations of PY was made using the conformational space search program CONFLEX6 from ${ }_{65}$ Conflex Corp. (Tokyo, Japan) running on Windows XP. The visualization and analysis interface BARISTA, a platform especially designed for conformational analyses, was used to create the initial parameters, and conformation search was carried out with MMFF94S (2006-11-24HGTEMP) 70 parameters using the default configuration resources, except for the upper limit value of conformational search that was set to cover an area of $10 \mathrm{kcal} / \mathrm{mol}$ within the most stable conformation $(\mathrm{SEL}=10) .{ }^{21}$ The GBSA continuum solvation method was also introduced to evaluate the solvation energy 75 contribution to the steric energy. ${ }^{22}$ The energy distribution of conformers was established under steric energy analysis. Those conformations that were chemically significant (accounting for $99.8 \%$ of the computed population) were grouped based on dihedral angle values (refer to Table 1SI in 80 the $\mathrm{ESI}^{\dagger}$ ) and the lowest-energy conformation of each group was used to create a potential energy map in which the two dihedral angles differing within each group were rotated independently $360^{\circ}$ in $10^{\circ}$ increments using the PM3 semiempirical method, including the solvent effects of water 85 as simulated by the COSMO solvation model. The potential energy conformation maps were constructed for each selected conformation with CAChe WorkSystem Pro from Fujitsu Ltd. (Tokyo, Japan) using the MOPAC_OpMap2_PM3_ $\mathrm{H}_{2} \mathrm{O}$ procedure. Several of the low-energy conformations obtained 90 from each generated potential energy map were chosen and reoptimized, and the lowest-energy conformations thus obtained were selected as the minimum energy conformations of PY. Optimized geometries of haptens were also calculated using the semi-empirical method PM3 with COSMO water 95 simulation using dihedral angle increments of $15^{\circ}$. Electrostatic potential energy surfaces were mapped over electron density isosurfaces using the same force field. The 
electron density probability value used for all calculations was 0.01 electrons $\AA^{-3}$.

\section{Buffers and solutions}

The following buffers were employed: $\mathrm{PB}, 100 \mathrm{mM}$ sodium phosphate buffer, pH 7.4; PBS, $10 \mathrm{mM}$ sodium phosphate buffer, pH 7.4 with $140 \mathrm{mM} \mathrm{NaCl}$; PBST, PBS containing $0.05 \%(\mathrm{v} / \mathrm{v})$ Tween $20 ; \mathrm{CB}, 50 \mathrm{mM}$ carbonate-bicarbonate buffer, $\mathrm{pH}$ 9.6; and washing solution, $150 \mathrm{mM} \mathrm{NaCl}$ containing $0.05 \%$ Tween 20 . PY and all other analytes were 10 prepared as concentrated solutions in $N, N$-dimethylformamide (DMF) and kept at $-20{ }^{\circ} \mathrm{C}$ in amber glass vials.

\section{Hapten synthesis}

The synthesis of hapten PYo5 was previously published. ${ }^{7}$ Hapten PYa6 was synthesized from methyl 15 methoxy(o-tolyl)carbamate (1) ${ }^{20}$ following the synthetic route detailed in Scheme 1 and hapten PYs5 was synthesized from commercial methyl (4-iodophenyl)hydrazine (12) following the procedure depicted in Scheme 2. Unless otherwise stated, organic extracts were successively washed with $\mathrm{H}_{2} \mathrm{O}$ and 20 brine, dried over anhydrous $\mathrm{Na}_{2} \mathrm{SO}_{4}$, and concentrated under vacuum. The characterization data of the synthetic intermediates can be found in the $\mathrm{ESI}^{\dagger}$. All solvents were purified by distillation and, if required, they were dried according to standard methods.

\section{${ }_{25}$ Synthesis of PYa6}

Methyl 4-iodo-2-methylphenyl(methoxy)carbamate (2) $\mathrm{Ag}_{2} \mathrm{SO}_{4}(1.097 \mathrm{~g}, 3.51 \mathrm{mmol})$ and $\mathrm{I}_{2}(0.893 \mathrm{~g}, 3.52 \mathrm{mmol})$ were successively added to a solution of methyl methoxy(o-tolyl)carbamate (1) $(680 \mathrm{mg}, 3.48 \mathrm{mmol})$ in glacial 30 acetic acid $(9 \mathrm{~mL})$, and the reaction mixture was stirred for 20 $\mathrm{h}$ at $\mathrm{rt}$ in the dark. After this time, a yellowish precipitate of AgI was formed, which was removed by filtration. The filtrate and washes were diluted with water and extracted with $\mathrm{CH}_{2} \mathrm{Cl}_{2}$. The combined organic extracts were successively 35 washed with aqueous $\mathrm{NaHCO}_{3}$, aqueous $\mathrm{Na}_{2} \mathrm{~S}_{2} \mathrm{O}_{7}$, brine, and dried. Evaporation of the solvent under vacuum gave 2 (1.093, $98 \%$ ) as a viscous oil that had a purity greater than $95 \%$, as judged by ${ }^{1} \mathrm{H}$ NMR analysis, and it was used in the next step without further purification.

40 Methyl 2-(bromomethyl)-4-iodophenyl(methoxy) carbamate (3). A solution of methoxycarbamate $2(810 \mathrm{mg}$, $2.50 \mathrm{mmol})$ and bromine $(3.21 \mathrm{~g}, 1.03 \mathrm{~mL}, 20.1 \mathrm{mmol}, 8$ equiv) in dry $\mathrm{CCl}_{4}(90 \mathrm{~mL})$ was irradiated with a mercury lamp $(125 \mathrm{~W})$ for $36 \mathrm{~h}$ at $\mathrm{rt}$. The reaction mixture was washed 45 with aqueous $\mathrm{Na}_{2} \mathrm{~S}_{2} \mathrm{O}_{7}$ and brine, and dried. The solvent was evaporated under vacuum to give an oily residue $(885 \mathrm{mg}$ ) consisting in a mixture of monobrominated compound 3 , the corresponding dibrominated derivative, and unreacted starting material that could not be separated by conventional ${ }_{50}$ chromatographic purification methods. The percent of $\mathbf{3}$ in the mixture was estimated to be $50-55 \%$ on the basis of the analysis of the mixture by NMR.

1-(4-Chlorophenyl)-1H-pyrazol-3-ol (6). A solution of sodium ethoxyde in ethanol, prepared by dissolving $\mathrm{Na}(882$ $55 \mathrm{mg}, 38.3 \mathrm{~mol})$ in anhydrous ethanol $(27 \mathrm{~mL})$, was added to a suspension of 4-chlorophenylhydrazine hydrochloride (4) $(3.00 \mathrm{~g}, 16.75 \mathrm{mmol})$ in dry toluene $(27 \mathrm{~mL})$ stirred under nitrogen at $40^{\circ} \mathrm{C}$. After stirring at the same temperature for 10 min, methyl acrylate $(7.21 \mathrm{~g}, 7.54 \mathrm{~mL}, 83.75 \mathrm{mmol})$ was 60 added drop wise during $20 \mathrm{~min}$ and the resulting mixture was stirred for $1.5 \mathrm{~h}$. The reaction mixture was concentrated in a rotary evaporator to remove most of the ethanol, then diluted with water $(300 \mathrm{~mL})$ and extracted with benzene. The benzene extracts were extracted with $5 \%$ sodium hydroxide and the ${ }_{65}$ combined aqueous basic phases were acidified with acetic acid to $\mathrm{pH} 6$ and extracted with benzene. The organic layer was washed, dried, and concentrated to give nearly pure 1-(4-chlorophenyl)pyrazolidin-3-one (5) (2.35 g, 71\%) as an amorphous solid.

70 The above solid $(1.265 \mathrm{~g}, 6.43 \mathrm{mmol})$ and $\mathrm{CuCl}(68 \mathrm{mg}$, $0.32 \mathrm{mmol})$ were dissolved in DMF $(13 \mathrm{~mL})$ and $\mathrm{O}_{2}$ was bubbled through the mixture during $3 \mathrm{~h}$ at $\mathrm{rt}$. The reaction mixture was diluted with $\mathrm{H}_{2} \mathrm{O}(100 \mathrm{~mL})$ and then stirred for 1 $\mathrm{h}$. The formed precipitate was filtered off, washed with water, 75 and dried to afford a brownish solid that was crystallized from benzene to give $6(993 \mathrm{mg}, 80 \%)$ as a slightly colored solid; mp $190-192{ }^{\circ} \mathrm{C}$ (from benzene), at $174-176{ }^{\circ} \mathrm{C}$ flake-like crystals were transformed into needle like crystals (lit., ${ }^{10} \mathrm{mp}$ $\left.181-182^{\circ} \mathrm{C}\right)$.

80 Methyl 2-((1-(4-chlorophenyl)-1H-pyrazol-3-yloxy) methyl)-4-iodophenyl(methoxy)carbamate (7). A mixture of pyrazolol 6 (186.3 $\mathrm{mg}, 0.96 \mathrm{mmol})$, benzyl bromide 3 (768 $\mathrm{mg}$ of the mixture obtained above from the bromination of methoxycarbamate 2, containing approximately $1.0 \mathrm{mmol}$ of ${ }_{85} 3$ ), and $\mathrm{CsCO}_{3}$ (759 mg, $2.32 \mathrm{mmol}$ ) in anhydrous DMF (6 $\mathrm{mL}$ ) was stirred at $\mathrm{rt}$ overnight. The reaction mixture was diluted with $\mathrm{H}_{2} \mathrm{O}$ and extracted with ethyl acetate. The organic layer was washed and dried. Filtration and evaporation of the solvent was followed by column chromatography, using 90 hexane-ethyl acetate $8: 2$ as eluent, to give $7(395 \mathrm{mg}, 80 \%)$ as an oil that solidified upon standing; $\mathrm{mp} 105-107^{\circ} \mathrm{C}$ (from methanol).

tert-Butyl 6-(3-((1-(4-chlorophenyl)-1H-pyrazol-3-yloxy) methyl)-4-(methoxy(methoxycarbonyl)amino)phenyl)hex-5

95 -ynoate (9). Dry DMF $(1.5 \mathrm{~mL})$ and triethylamine $(1.2 \mathrm{~mL})$ were added to a mixture of aryl iodide $7(241.5 \mathrm{mg}, 0.468$ $\mathrm{mmol})$, tert-butyl hex-5-ynoate (8) $(117.9 \mathrm{mg}, 0.702 \mathrm{mmol})$, $\mathrm{Cl}_{2} \mathrm{Pd}\left(\mathrm{PPh}_{3}\right)_{2}\left(9.3 \mathrm{mg}, 1.310^{-2} \mathrm{mmol}\right)$, and $\mathrm{CuI}(3.6 \mathrm{mg}, 1.9$ $10^{-2} \mathrm{mmol}$ ) under nitrogen. The mixture was degassed through 100 several freeze-thaw cycles, stirred at $\mathrm{rt}$ for $30 \mathrm{~min}$ and then at $60{ }^{\circ} \mathrm{C}$ for $4 \mathrm{~h}$. The resulting brownish reaction mixture was cooled down, filtered through cotton and most of the triethylamine was removed under vacuum. The residue was diluted with ethyl acetate and washed, dried, and concentrated.

${ }_{105}$ Purification by silica gel chromatography, using hexane-ethyl acetate $9: 1$ as eluent, afforded compound 9 (255 mg, 98\%) as an oil.

tert-Butyl 6-(3-((1-(4-chlorophenyl)-1H-pyrazol-3-yloxy) methyl)-4-(methoxy(methoxycarbonyl)amino)phenyl)

110 hexanoate (10). A solution of alkyne $9(243 \mathrm{mg}, 0.439 \mathrm{mmol})$ and Wilkinson's catalyst $(12.2 \mathrm{mg}, 0.013 \mathrm{mmol}, 3 \%)$ in tetrahydrofurane $(3 \mathrm{~mL})$ was evacuated and purged under an atmosphere of hydrogen gas. Then, the hydrogen pressure was regulated to 4 atmospheres and the reaction mixture was 115 stirred at $\mathrm{rt}$ for $16 \mathrm{~h}$, the solvent was removed under vacuum, and the residue was purified by chromatography, using hexane-ethyl acetate 9:1 as eluent, to furnish compound $\mathbf{1 0}$ (220 mg, 92\%).

6-(3-((1-(4-Chlorophenyl)-1H-pyrazol-3-yloxy)methyl)-4120 (methoxy(methoxycarbonyl)amino)phenyl)hexanoic acid (11, hapten PYa6). A solution of the tert-butyl ester 10 (203 $\mathrm{mg}, 0.364 \mathrm{mmol})$ in trifluoroacetic acid $(1.5 \mathrm{~mL})$ and $\mathrm{CH}_{2} \mathrm{Cl}_{2}$ $(1.5 \mathrm{~mL})$ was stirred at $0{ }^{\circ} \mathrm{C}$ until TLC [developed with hexane-ethyl acetate (7:3)] showed completion of the reaction ${ }_{125}$ (about 1 to $1.5 \mathrm{~h}$ ). The reaction mixture was concentrated under vacuum without heating and the residue obtained was 
purified by silica gel chromatography, using $4 \%$ of methanol in $\mathrm{CHCl}_{3}$ as eluent, to give the hapten PYa6 (11) $(182 \mathrm{mg}$, $99 \%)$ as a slightly colored viscous oil; $\delta_{\mathrm{H}}\left(\mathrm{CDCl}_{3}\right) 7.70(1 \mathrm{H}$, d, $J=2.6 \mathrm{~Hz}, \mathrm{H}-5 \mathrm{Pz}), 7.55(2 \mathrm{H}, \mathrm{m}$, part AA' of the AA'BB' 5 system, $J=8.8,2.5,0.5 \mathrm{~Hz}, \mathrm{H}-2$, and $\mathrm{H}-6 \mathrm{ClPh}), 7.47(1 \mathrm{H}, \mathrm{d}$, $J=1.8 \mathrm{~Hz}, \mathrm{H}-3 \mathrm{Ph}), 7.37(2 \mathrm{H}, \mathrm{m}$, part BB' of the AA'BB' system, $J=8.8,2.5,0.5 \mathrm{~Hz}, \mathrm{H}-3$, and $\mathrm{H}-5 \mathrm{ClPh}), 7.27(1 \mathrm{H}, \mathrm{d}$, $J=8.1 \mathrm{~Hz}, \mathrm{H}-6 \mathrm{Ph}), 7.18(1 \mathrm{H}, \mathrm{dd}, J=8.1,1.8 \mathrm{~Hz}, \mathrm{H}-5 \mathrm{Ph})$, $5.94(1 \mathrm{H}, \mathrm{d}, J=2.6 \mathrm{~Hz}, \mathrm{H}-4 \mathrm{Pz}), 5.30\left(2 \mathrm{H}, \mathrm{s}, \mathrm{OCH}_{2}\right), 3.79$

$10\left(3 \mathrm{H}, \mathrm{s}, \mathrm{CO}_{2} \mathrm{CH}_{3}\right), 3.75\left(3 \mathrm{H}, \mathrm{s}, \mathrm{NOCH}_{3}\right), 2.66(2 \mathrm{H}, \mathrm{t}, J=7.7$ $\mathrm{Hz}, \mathrm{H}-6), 2.34(2 \mathrm{H}, \mathrm{t}, J=7.4 \mathrm{~Hz}, \mathrm{H}-2), 1.64(4 \mathrm{H}, \mathrm{m}, \mathrm{H}-3$ and $\mathrm{H}-5)$ and $1.40(2 \mathrm{H}, \mathrm{m}, \mathrm{H}-4) ; \delta_{\mathrm{C}}\left(\mathrm{CDCl}_{3}\right) 179.01(\mathrm{C}-1), 164.30$ $(\mathrm{C}-3 \mathrm{Pz}), 155.94\left(\mathrm{NCO}_{2}\right), 143.46(\mathrm{C}-1 \mathrm{Ph}), 138.59(\mathrm{C}-1$ $\mathrm{ClPh}), 134.92$ and $134.40(\mathrm{C}-2$ and $\mathrm{C}-4 \mathrm{Ph}), 130.61$ (C-4 $\left.{ }_{15} \mathrm{ClPh}\right), 129.34(\mathrm{C}-3$ and $\mathrm{C}-5 \mathrm{ClPh}), 128.87$ and $128.58(\mathrm{C}-3$ and $\mathrm{C}-5 \mathrm{Ph}), 127.73(\mathrm{C}-5 \mathrm{Pz}), 127.17(\mathrm{C}-6 \mathrm{Ph}), 118.93(\mathrm{C}-2$ and $\mathrm{C}-6 \mathrm{ClPh}), 94.33(\mathrm{C}-4 \mathrm{Pz}), 66.95\left(\mathrm{OCH}_{2}\right), 61.94\left(\mathrm{NOCH}_{3}\right)$, $53.52\left(\mathrm{CO}_{2} \mathrm{CH}_{3}\right), 35.28(\mathrm{C}-6), 33.80(\mathrm{C}-2), 30.69(\mathrm{C}-5), 28.47$ (C-4) and $24.43(\mathrm{C}-3) ; v_{\max } / \mathrm{cm}^{-1}(\mathrm{NaCl}) 3400-2800,2933$, $202861,1735,1707,1546,1501,1481,1358,1094$ and $751 ; \mathrm{m} / \mathrm{z}$ (EI) 441 (8\%), 440 (6), 439 (22), 308 (9), 278 (10), 277 (18), 247 (16), 277 (17), 276 (10), 246 (100) and 194 (59); m/z (FAB) calcd for $\mathrm{C}_{25} \mathrm{H}_{29} \mathrm{ClN}_{3} \mathrm{O}_{6}\left(\mathrm{M}^{+}+\mathrm{H}\right)$ 502.17449, found $502.17539 ; \lambda_{\max }(\mathrm{PB}) / \mathrm{nm} 280\left(\varepsilon / \mathrm{dm}^{3} \mathrm{~mol}^{-1} \mathrm{~cm}^{-1} 12.1\right)$ and 260 25 (11.7).

\section{Synthesis of PYs5}

1-(4-Iodophenyl)-1H-pyrazol-3-ol (14). A $1 \mathrm{M}$ solution of potassium tert-butoxide in tert-butanol $(1.2 \mathrm{~mL}, 1.2 \mathrm{mmol})$ was added to a solution of (4-iodophenyl)hydrazine (12) (234

$30 \mathrm{mg}, 1 \mathrm{mmol})$ in anhydrous toluene $(1.2 \mathrm{~mL})$ at $\mathrm{rt}$ under nitrogen. The mixture was warmed to $50{ }^{\circ} \mathrm{C}$ and then drop wise treated with tert-butyl acrylate $(135 \mathrm{mg}, 153 \mu \mathrm{L}, 1.05$ mmol). The reaction mixture was stirred at $50{ }^{\circ} \mathrm{C}$ for a few minutes, then cooled to rt, diluted with benzene, and extracted 35 with $5 \%$ aqueous $\mathrm{KOH}$. The aqueous layer was treated with excess $\mathrm{CO}_{2}$ and the fuchsia solid formed was extracted with ethyl acetate (5 times). The combined organic layers were washed and dried. Filtration and evaporation of the solvent afforded a solid that was crystallized from benzene-acetone to

40 give crystals of 1-(4-iodophenyl)pyrazolidin-3-one (13) (179 $\mathrm{mg}, 62 \%$ ) as a brown solid; $\mathrm{mp}$ 142-143 ${ }^{\circ} \mathrm{C}$ (from benzene-acetone).

A mixture of the compound $\mathbf{1 3}$ obtained above $(164 \mathrm{mg}$, $0.577 \mathrm{mmol})$ and $\mathrm{CuCl}(2.5 \mathrm{mg}, 0.03 \mathrm{mmol})$ in DMF $(2.5 \mathrm{~mL})$ 45 was stirred in the air until all the starting material was consumed (about $5 \mathrm{~h}$ ). The reaction mixture was diluted with $\mathrm{H}_{2} \mathrm{O}$ and the solid formed was collected by filtration, washed with cold water, and dried under vacuum to obtain pure 1-(4-iodophenyl)-1H-pyrazol-3-ol (14) (160 mg, 97\%) as a so cream color solid; needle-like crystals from hexane-ethyl acetate began to sublimate at $190{ }^{\circ} \mathrm{C}$ and melted at $222-224$ ${ }^{\circ} \mathrm{C}$.

tert-Butyl 5-(4-(3-hydroxy-1H-pyrazol-1-yl)phenylthio) pentanoate (17). tert-Butyl 5-mercaptopentanoate (16) was ${ }_{55}$ prepared from tert-butyl 5-bromopentanoate (15) and thiourea with very high yield via formation of the thiouronium salt followed by cleavage with sodium pyrosulfite. ${ }^{11}$ Then, a mixture of iodophenyl-pyrazolol $14(200 \mathrm{mg}, 0.70 \mathrm{mmol})$, thiol $16(200 \mathrm{mg}, 1.05 \mathrm{mmol}), \mathrm{K}_{2} \mathrm{CO}_{3}(193 \mathrm{mg}, 1.40 \mathrm{mmol})$, ${ }_{60} \mathrm{CuI}(7 \mathrm{mg}, 0.035 \mathrm{mmol})$, and ethylenglycol $(78 \mu \mathrm{L}, 1.40$ $\mathrm{mmol})$ in 2-propanol $(0.7 \mathrm{~mL})$ was degassed through three freeze-pump-thaw cycles, sealed under vacuum, and heated at $80-85^{\circ} \mathrm{C}$ with stirring for $24 \mathrm{~h}$. The cooled reaction mixture was diluted with ethyl acetate and washed, dried, and ${ }_{65}$ concentrated. The brownish oily residue was purified by column chromatography, using hexane-ethyl acetate mixtures from $9: 1$ to $7: 3$ as eluent, to give, in order of elution, unreacted starting pyrazolol 14 (54 $\mathrm{mg}, 73 \%$ conversion) and compound $17(130 \mathrm{mg}, 70 \%)$ as a solid; $\mathrm{mp} 113-114{ }^{\circ} \mathrm{C}$ (from 70 hexane-isopropanol).

tert-Butyl 5-(4-(3-(2-(methoxy(methoxycarbonyl)amino) benzyloxy)-1H-pyrazol-1-yl)phenylthio)pentanoate (19). A mixture of compound $17(99 \mathrm{mg}, 0.284 \mathrm{mmol})$, methyl 2-(bromomethyl)phenyl(methoxy)carbamate (18, prepared by 75 benzylic bromination of tolylcarbamate 1 with $N$ bromosuccinimide and azaisobutyronitrile in $\mathrm{CCl}_{4}$ at reflux $)^{8}$ (117 mg, $0.427 \mathrm{mmol}$ ), and $\mathrm{CsCO}_{3}(139 \mathrm{mg}, 0.427 \mathrm{mmol})$ in anhydrous DMF $(1.2 \mathrm{~mL})$ was stirred at $\mathrm{rt}$ overnight under nitrogen. The reaction mixture was diluted with ethyl acetate 80 and washed, dried, filtered, and then evaporated to dryness. Purification by column chromatography, using hexane-ethyl acetate $9: 1$ as eluent, afforded compound $19(134 \mathrm{mg}, 89 \%)$ as a viscous oil.

5-(4-(3-(2-(Methoxy(methoxycarbonyl)amino)benzyloxy)${ }_{85}$ 1H-pyrazol-1-yl)phenylthio)pentanoic acid (20, hapten PYs5). A solution of the tert-butyl ester 19 (107 mg, 0.197 mmol) in a $1: 1$ mixture of trifluoroacetic acid and $\mathrm{CH}_{2} \mathrm{Cl}_{2}(4$ $\mathrm{mL}$ ) was stirred at $0{ }^{\circ} \mathrm{C}$ for $1 \mathrm{~h}$. Work-up of the reaction mixture as described above for the hydrolysis of $\mathbf{1 0}$ to $\mathbf{1 1}$, 90 followed by chromatography on silica gel and using $\mathrm{CHCl}_{3}-$ methanol 95:5 as eluent, afforded hapten PYs5 (20) $(86 \mathrm{mg}, 90 \%)$ as a colorless viscous oil; $\delta_{\mathrm{H}}\left(\mathrm{CDCl}_{3}\right) 7.69(1 \mathrm{H}$, d, $J=2.6 \mathrm{~Hz}, \mathrm{H}-5 \mathrm{Pz}), 7.66(1 \mathrm{H}, \mathrm{m}, \mathrm{H}-4 \mathrm{Ph}), 7.51(2 \mathrm{H}, \mathrm{m}$, part AA' of the AA'BB' system, $J=8.8,2.5,0.5 \mathrm{~Hz}, \mathrm{H}-2$ and $\left.{ }_{95} \mathrm{H}-6 \mathrm{SPh}\right), 7.40-7.35$ (3H, m, H-3, H-5 and H-6 Ph overlapped with the part BB' of the AA'BB' system corresponding to $\mathrm{H}-3$ and $\mathrm{H}-5 \mathrm{SPh}), 5.90(1 \mathrm{H}, \mathrm{d}, J=2.6 \mathrm{~Hz}, \mathrm{H}-4 \mathrm{Pz}), 5.34(2 \mathrm{H}, \mathrm{s}$, $\left.\mathrm{OCH}_{2}\right), 3.79\left(3 \mathrm{H}, \mathrm{s}, \mathrm{CO}_{2} \mathrm{CH}_{3}\right), 3.75\left(3 \mathrm{H}, \mathrm{s}, \mathrm{NOCH}_{3}\right), 2.91$ $(2 \mathrm{H}, \mathrm{t}, J=7.1 \mathrm{~Hz}, \mathrm{H}-5), 2.36(2 \mathrm{H}, \mathrm{t}, J=7.0 \mathrm{~Hz}, \mathrm{H}-2)$ and 1.72 ${ }_{00}(4 \mathrm{H}, \mathrm{m}, \mathrm{H}-3$ and $\mathrm{H}-4) ; \delta_{\mathrm{C}}\left(\mathrm{CDCl}_{3}\right) 178.86(\mathrm{C}-1), 164.10(\mathrm{C}-3$ $\mathrm{Pz}), 155.84\left(\mathrm{NCO}_{2}\right), 138.48$ and $137.30(\mathrm{C}-1$ and $\mathrm{C}-2 \mathrm{Ph})$, $134.77(\mathrm{C}-1 \mathrm{SPh}), 132.69(\mathrm{C}-4 \mathrm{SPh}), 130.95$ (C-3 and C-5 $\mathrm{SPh}), 128.85,128.80$ and $128.48(\mathrm{C}-3, \mathrm{C}-4$ and $\mathrm{C}-5 \mathrm{Ph})$, 127.66 (C-5 Pz), 127.01 (C-6 Ph), 118.29 (C-2 and C-6 SPh), $10594.05(\mathrm{C}-4 \mathrm{Pz}), 66.79\left(\mathrm{OCH}_{2}\right), 62.09\left(\mathrm{NOCH}_{3}\right), \quad 53.54$ $\left(\mathrm{CO}_{2} \mathrm{CH}_{3}\right), 33.99(\mathrm{C}-5), 33.35(\mathrm{C}-2), 28.33(\mathrm{C}-4)$ and 23.58 $(\mathrm{C}-3) ; v_{\max } / \mathrm{cm}^{-1}(\mathrm{NaCl}) 3500-2800,3142,3044,2954,1793$, $1708,1545,1480,1358,1267,1100$ and $737 ; \mathrm{m} / \mathrm{z}$ (EI) 485 $\left(\mathrm{M}^{+}, 0.1 \%\right), 467$ (1), 454 (1.5), 453 (4), 437 (6), $425(7), 424$ 110 (18), 423 (76), 422 (4), 379 (3), 291 (30), 162 (12) and 132 (100); m/z (EI) calcd for $\mathrm{C}_{24} \mathrm{H}_{27} \mathrm{~N}_{3} \mathrm{O}_{6} \mathrm{~S} 485.16206$, found 485.16249; $\lambda_{\max }(\mathrm{PB}) / \mathrm{nm} 280\left(\varepsilon / \mathrm{dm}^{3} \mathrm{~mol}^{-1} \mathrm{~cm}^{-1} 19.2\right)$ and 260 (8.15).

\section{Protein conjugate preparation}

15 All of the synthesized haptens contained a free carboxylic group for protein conjugation. The hapten-to-protein MR of each bioconjugate was calculated by MALDI-TOF-MS and by differential absorbance measurements. For MALDI-TOF-MS analysis, a fraction of each conjugate solution was extensively 120 dialyzed against pure water at $4{ }^{\circ} \mathrm{C}$ and lyophilized. Samples were resuspended in acetonitrile-water $7: 3(\mathrm{v} / \mathrm{v})$ containing $0.1 \%$ trifluoroacetic acid, and they were charged into the plate in between two layers of sinapinic acid.

Immunizing conjugates. BSA conjugates were prepared by 125 the active ester procedure. Briefly, $20 \mu \mathrm{mol}$ of hapten in DMF was mixed with $20 \mu \mathrm{mol}$ of $N$-hydroxysuccinimide and $20 \mu \mathrm{mol}$ of $N, N$-dicyclohexylcarbodiimide also in DMF. Additional DMF was added to bring the final concentration of all reagents to $50 \mathrm{mM}$. Hapten activation was left to occur 
overnight at $\mathrm{rt}$ in amber vials. The day after, the reaction was centrifuged and the supernatant was collected. Next, $200 \mu \mathrm{L}$ of activated hapten solution was added drop wise to $1.0 \mathrm{~mL}$ of a $15.0 \mathrm{mg} / \mathrm{mL}$ BSA solution in CB. The coupling reaction was 5 allowed to happen during $4 \mathrm{~h}$ at $\mathrm{rt}$ with moderate stirring. The initial hapten-to-protein MR in the reaction mixture was approximately $44: 1$. Finally, the conjugate was separated from uncoupled hapten by gel filtration on Sephadex G-25, using $\mathrm{PB}$ as eluent. The purified bioconjugate was diluted to 1.0 $10 \mathrm{mg} / \mathrm{mL}$ with $\mathrm{PB}$ and stored at $-20{ }^{\circ} \mathrm{C}$. For differential absorbance measurements, the absorbance values of the conjugate at 280 and $260 \mathrm{~nm}$ were considered.

Coating conjugates. In this case, the coupling reaction of the hapten to the carrier protein was accomplished by the 15 mixed anhydride procedure. Basically, $18 \mu \mathrm{mol}$ of hapten was dissolved in $180 \mu \mathrm{L}$ of DMF and mixed with $18 \mu$ mol of tributylamine and $18 \mu \mathrm{mol}$ of isobutyl chloroformate also in DMF. The concentration of all reagents was brought to 90 $\mathrm{mM}$ with DMF and the hapten was left to be activated during $201 \mathrm{~h}$ at $\mathrm{rt}$. Next, $100 \mu \mathrm{L}$ of activated hapten solution was added drop wise to $2.0 \mathrm{~mL}$ of a $15.0 \mathrm{mg} / \mathrm{mL}$ OVA solution in CB. The coupling reaction was carried out during $2.5 \mathrm{~h}$ at $\mathrm{rt}$ with moderate stirring. The initial hapten-to-protein MR in the reaction mixture was approximately 13:1. Conjugates were 25 processed and stored as described above.

Tracer conjugates. The mixed anhydride method was also used to prepare the corresponding enzyme conjugates. First, haptens were activated as described above and a 1/10 dilution in DMF was prepared after the incubation step. Next, $100 \mu \mathrm{L}$ 30 of this dilution was added drop wise to a $1.0 \mathrm{~mL}$ solution of $\mathrm{HRP}$ at $2.2 \mathrm{mg} / \mathrm{mL}$ in $\mathrm{CB}$. The coupling reaction was incubated for $4 \mathrm{~h}$ at $\mathrm{rt}$ with moderate stirring. The initial hapten-to-protein $\mathrm{MR}$ in the reaction mixture was approximately 18:1. The tracer was separated from uncoupled 35 hapten by gel filtration on Sephadex G-25. For differential absorbance measurements, the absorbance values of the conjugate at 400 and $280 \mathrm{~nm}$ were considered in this case. The purified tracer was brought to $1.0 \mathrm{mg} / \mathrm{mL}$ with $\mathrm{PB}$ and diluted 1:1 (v/v) with PBS containing 1\% (w/v) BSA and $0.01 \%(\mathrm{w} / \mathrm{v})$ 40 thimerosal. The conjugate was stored at $-20{ }^{\circ} \mathrm{C}$ in amber glass vials for long-term preservation and a working aliquot was kept at $4{ }^{\circ} \mathrm{C}$.

\section{Antiserum production}

Animal manipulation was performed in compliance with the 45 laws and guidelines of the Spanish Ministry of Science and Innovation (RD 1201/2005 and law 32/2007) and according to the European Directive 2003/65/EC (amending general Council Directive 86/609/EEC) concerning the protection of animals used for experimental and other scientific purposes. ${ }_{50}$ Two New Zealand white female rabbits weighing 1-2 kg were immunized by subcutaneous injection with $0.3 \mathrm{mg}$ of conjugate BSA-PYo5, BSA-PYa6, or BSA-PYs5 following described procedures. ${ }^{23}$ For further details see the ESI ${ }^{\dagger}$.

\section{Competitive immunoassays}

${ }_{55}$ All antisera were evaluated in the two classical cELISA formats using both homologous and heterologous conjugates. Eight-channel electronic pipettes were employed for rapid and precise liquid dispensing. Microplates were washed four times with washing solution using a 96-channel ELx405 washer ${ }_{60}$ from BioTek Instruments (Winooski, VT). After the assay, the absorbance was read at $492 \mathrm{~nm}$ with a reference wavelength at $650 \mathrm{~nm}$. Sigmoidal curves were mathematically fitted to a four-parameter logistic equation using the SigmaPlot software package from SPSS Inc. (Chicago, IL). The antiserum titer ${ }_{65}$ was defined as the reciprocal of the dilution that results in a maximum absorbance value $\left(\mathrm{A}_{\max }\right)$ around 1.0 reached at the zero dose of analyte when assayed using the indirect competitive format with the homologous conjugate at 1.0 $\mu \mathrm{g} / \mathrm{mL}$. Antibody affinity was estimated as the concentration 70 of analyte that reduced $50 \%\left(\mathrm{IC}_{50}\right)$ the $\mathrm{A}_{\max }$ value, and the assay limit of detection was defined as the $\mathrm{IC}_{10}$ of the inhibition curve.

Conjugate-coated indirect assays. ELISA plates were coated with $100 \mu \mathrm{L}$ per well of OVA conjugate solution at 1.0 75 and $0.1 \mu \mathrm{g} / \mathrm{mL}$ in $\mathrm{CB}$ by overnight incubation at rt. Serial three-fold antisera dilutions (from $1 / 1500$ to $1 / 5 \times 10^{5}$ ) were prepared in PBST. Each plate column received a complete standard curve of the analyte in PBS $(50 \mu \mathrm{L}$ per well) followed by a given antiserum dilution $(50 \mu \mathrm{L}$ per well). The 80 same distribution of the reagents was repeated for each plate with a different conjugate. The immunological reaction took place during $1 \mathrm{~h}$ at $\mathrm{rt}$, and plates were washed again as described. Next, $100 \mu \mathrm{L}$ per well of a $1 / 10000$ dilution of goat anti-rabbit IgG peroxidase conjugate in PBST was added, and 85 plates were incubated $1 \mathrm{~h}$ at $\mathrm{rt}$. After washing four times, the retained peroxidase activity was determined by addition of $100 \mu \mathrm{L}$ per well of freshly prepared $2.0 \mathrm{mg} / \mathrm{mL}$ of OPD and $0.012 \%(\mathrm{v} / \mathrm{v}) \mathrm{H}_{2} \mathrm{O}_{2}$ in $25 \mathrm{mM}$ citrate and $62 \mathrm{mM}$ sodium phosphate buffer, $\mathrm{pH}$ 5.4. The enzymatic reaction was stopped 90 after 10 min with $100 \mu \mathrm{L}$ of $2.5 \mathrm{M} \mathrm{H}_{2} \mathrm{SO}_{4}$.

Antibody-coated direct assays. Microplates were coated with $100 \mu \mathrm{L}$ per well of a $1 / 3000,1 / 10000$, and $1 / 30000$ dilution of a given antiserum in $\mathrm{CB}$ by overnight incubation at rt. After four washes, $50 \mu \mathrm{L}$ per well of PY standard curve 95 was dispensed to each plate column and immediately $50 \mu \mathrm{L}$ per well of a different concentration of a given enzyme tracer was added. In this case, serial three-fold dilutions in PBST of the HRP conjugate (from 600 to $2 \mathrm{ng} / \mathrm{mL}$ ) were prepared. The same array of reagent concentrations was distributed in 100 another plate that had previously been coated with a different antiserum. The immunological reaction was carried out during $1 \mathrm{~h}$ at $\mathrm{rt}$ and the enzyme activity was revealed as described before.

\section{Acknowledgements}

${ }_{105}$ We thank Joaquin J. Barjau for the preparation of some of the intermediates used in the synthesis of the haptens, and Laura López-Sánchez and Ana Izquierdo-Gil for excellent technical assistance. We also thank Dr. Reinhard Kirstgen from BASF for kindly providing strobilurin analogues and hapten 110 synthesis precursors.

This work was supported by Ministerio de Educación y Ciencia (AGL2006-12750-C02-01/02/ALI) and cofinanced by FEDER funds. J.V.M. was hired by the CSIC under a Ramón y Cajal contract financed by Ministerio de Ciencia e 115 Innovación and the European Social Fund.

\section{Notes and references}

${ }^{a}$ Department of Organic Chemistry, Universitat de València, Doctor Moliner 50, 46100 Burjassot, València, Spain. Fax: +34-963544328; Tel: +34-963544509; E-mail: antonio.abad@uv.es

$120{ }^{b}$ Department of Biotechnology, IATA-CSIC, Agustí Escardino 7, 46980 Paterna, València, Spain. Fax: +34-963636301; Tel: +34-963636301; Email:aabad@iata.csic.es

Electronic Supplementary Information (ESI) available: Full characterization data of all the intermediate compounds in the synthesis of 125 haptens PYa6 and PYs5 are given as well as complementary data about 
conformational studies and copies of ${ }^{1} \mathrm{H}$ NMR and MS spectra. See DOI: $10.1039 / b 000000 x$

1 K. Landsteiner, Koninkl. Akad. Wet. Amst. Verslag, 1921, 30, 329.

2 For example, a) S. Lu, Y. Zhang, J. Liu, C. Zhao, W. Liu and R. Xi, J. Agric. Food Chem., 2006, 54, 6995; b) J. V. Mercader, C. SuárezPantaleón, C. Agulló, A. Abad-Somovilla and A. Abad-Fuentes, J. Agric. Food Chem., 2008, 56, 2581.

3 a) Y. J. Kim, Y. A. Cho, H. S. Lee, Y. T. Lee, S. J. Gee and B. D. Hammock, Anal. Chim. Acta, 2003, 475, 85; b) Y. H. Liu, M. J. Jin,

10 W. J. Gui, J. L. Cheng, Y. R. Guo and G. N. Zhu, Anal. Chim. Acta, 2007, 591, 173.

4 a) Z. Wang, Y. Zhu, S. Ding, F. He, R. C. Beier, J. Li, H. Jiang, C. Feng, Y. Wan, S. Zhang, Z. Kai, X. Yang and J. Shen, Anal. Chem., 2007, 79, 4471; b) Review, Z. L. Xu, Y. D. Shen, R. C. Beier, J. Y.

15 Yang, H. T. Lei, H. Wang and Y. M. Sun, Anal. Chim. Acta, 2009, 647, 125.

5 a) D. W. Barlett, J. M. Clough, C. R. A. Godfrey, J. R. Godwin, A. A. Hall, S. P. Heaney and S. J. Maund, Pestic. Outlook, 2001, 12, 143; b) H. Sauter, in Modern Crop Protection Compounds, ed. W.

20 Kraemer and U. Schirmer, Willey-VCH, Weinheim, Germany, 2007, pp. 457-495.

6 For example, a) B. Ballesteros, D. Barceló, F. Sánchez-Baeza, F. Camps and M. P. Marco, Anal. Chem., 1998, 70, 4004; b) R. Galve, F. Camps, F. Sánchez-Baeza and M. P. Marco, Anal. Chem., 2000,

25 72, 2237; c) W. L. Shelver, Y. S. Keum, H. J. Kim, D. Rutherford, H. H. Hakk, A. Bergman and Q. X. Li, J. Agric. Food Chem., 2005, 53, 3840 .

7 J. V. Mercader, C. Suárez-Pantaleón, C. Agulló, A. Abad-Somovilla and A. Abad-Fuentes, J. Agric. Food Chem., 2008, 56, 7682.

308 M. Ohnishi, S. Tajima, Y. Yamamoto and H. Kanno, Eur. Pat., 619301 A2, 1994.

9 A. Liu, X. Wang, X. Ou, M. Huang, C. Chen, S. Liu, L. Huang, X. Liu, C. Zhang, Y. Zheng, Y. Ren, L. He and J. Yao, J. Agric. Food Chem., 2008, 5, 6562.

3510 H. König, N. Götz, U. Klein and K. Eller, US Pat., 5922886 A1, 1999.

11 A. Polina, K. Kalina, H. Karsten and T. Dimiter, Central Eur. J. Chem., 2005, 3, 658 .

12 a) M. Adamczyk, A. Buko, Y. Y. Chen, J. R. Fishpaugh, J. C. Gebler and D. D. Johnson, Bioconjugate Chem., 1994, 5, 631; b) K. V. Singh, J. Kaur, G. C. Varshney, M. Raje and C. R. Suri, Bioconjugate Chem., 2004, 15, 168.

13 R. C. Boro, K. V. Singh and C. R. Suri, J. AOAC Int., 2009, 92, 1773.

14 C. S. Ra and G. Park, Bull. Korean Chem. Soc., 2002, 23, 1199.

4515 N. Sanvicens, F. Sánchez-Baeza and M. P. Marco, J. Agric. Food Chem., 2003, 51, 3924

16 a) R. Matsuo, K. Nishi, K. Morimune, H. Okawa and S. Miyake, Jap. Pat., 2005035893, 2005; b) J. J. Manclús, J. Primo and A. Montoya, J. Agric. Food Chem., 1996, 44, 4052.

5017 M. Lee, P. Lloyd, X. Zhang, J. M. Schallhorn, K. Sugimoto, A. G. Leach, G. Sapiro and K. N. Houk, J. Org. Chem., 2006, 71, 5082

18 G. Bartoli, M. Bosco, A. Carlone, R. Dalpozzo, E. Marcantoni, P. Melchiorre and L. Sambri, Synthesis, 2007, 3489.

19 S. Connolly, C. Bennion, S. Botterell, P. J. Croshaw, C. Hallam, K.

55 Hardy, P. Hartopp, C. G. Jackson, S. J. King, L. Lawrence, A. Mete, D. Murray, D. H. Robinson, G. M. Smith, L. Stein, I. Walters, E. Wells and W. J. Withnall, J. Med. Chem., 2002, 45, 1348.

20 B. Mueller, H. Sauter, F. Roehl, R. Doetzer, G. Lorenz and E. Ammermann, Pat., WO 9315046 A1, 1993

6021 a) H. Goto and E. Osawa, J. Am. Chem. Soc., 1989, 111, 8950; b) H. Goto and E. Osawa, J. Chem. Soc., Perkin Trans. 2, 1993, 187.

22 D. Qiu, P. S. Shenkin, F. P. Hollinger and W. C. Still, J. Phys. Chem. A, 1997, 101, 3005.

23 C. Suárez-Pantaleón, J. V. Mercader, C. Agulló, A. Abad-Somovilla 65 and A. Abad-Fuentes, J. Agric. Food Chem., 2010, 58, 8502.

Limited amounts of the newly described immunoreagents are available upon request for evaluation. 